\title{
Molecular Interactions in Dilute Supercritical Mixtures: Molecular Dynamics Investigation
}

(Grant DE-FG02-87ER13714)

\author{
A Progress Report, covering the period \\ $7 / 31 / 90$ to $7 / 31 / 91$ \\ submitted to \\ The Department of Energy \\ Chicago Operations Office
}

by

\author{
Pablo G. Debenedetti \\ Associate Professor \\ Department of Chemical Engineering \\ Princeton University \\ Princeton, NJ 08544-5263
}

$(690) 258-5480$

\begin{abstract}
DISCLAIMER
This report was prepared as an account of work sponsored by an agency of the United States Government. Neither the United States Government nor any agency thereof, nor any of their employees, makes any warranty, express or implied, or assumes any legal liability or responsibility for the accuracy, completeness, or usefulness of any information, apparatus, product, or process disclosed, or represents that its use would not infringe privately owned rights. Reference herein to any specific commercial product, process, or service by trade name, trademark, manufacturer, or otherwise does not necessarily constitute or imply its endorsement, recommendation, or favoring by the United States Government or any agency thereof. The views and opinions of authors expressed herein do not necessarily state or reflect those of the United States Government or any agency thereof.
\end{abstract}


This progress report summarizes risearch carried out under grant DE-FG0287ER13714, during the 12 -month period $7 / 31 / 90$ through $7 / 31 / 91$.

\section{IECHNICALDISCUSSION}

In recent years, considerable effort has been devoted to the study of molecular interactions in supercritical mixtures (Kim and Johnston, 1987a,b; Brennecke and Eckert, 1989 a,b; Brennecke et al., 1990 a,b; Petsche and Debenedetti, 1989, 1991; Cochran and Lee, 1989; Wu et al., 1990). This interest has been motivalad by the realization that in these systems, the nature of the local environment surrounding solute molecules (microstructure) can be dramatically different from the bulk. Hence, progress toward a predictive, quantitative understanding of supercritical mixtures must be based on a firm grasp of the molecular, microscopic behavior that underlies the observable bulk properties and phase behavior.

With this in mind, we initiated a collaboration with Professor Charles A. Eckert (Chemical Engineering Department; Georgia Tech). Professor Eckert is doing pioneering work on the application of spectroscopic techniques to the study of molecular interactions in supercritical mixtures. Our collaboration represents the first direct comparison between spectroscopic measurements (performed at Georgia Tech) and computer simulations (performed at Princeton) of supercritical mixtures.

We performed a series of simulations (Knutson et al., 1991; enclosed) aimed at investigating the nature of the microstructure around solute molecules in a supercritical solvent, in the limit of infinite dilution (no solute-solute interactions). The choice of model system (pyrene in supercritical carbon dioxide) and state conditions (5-20 moles/liter; $37^{\circ} \mathrm{C}$ and $\left.75^{\circ} \mathrm{C}\right)$ was done so as to match corresponding fluorescence experiments performed at Georgia Tech.

Previous observations by Eckert and his group were consistent with the concept of a pronounced local density augmentation of the solvent around the solute (Brennecke et al., 1990b). However, because the interpretation of spectra in terms of molecular events is complex, it had not been possible to quantify the spectroscopic observations neither in terms of the number of solvent molecules involved in the local density augmentation, nor in terms of the extent of the region where the local and bulk regions differ appreciably.

The simulations confirmed that for attractive mixtures (Petsche and Debenedetti, 1991) of interest in supercritical extraction, the solvent's density in the vicinity of the solute is much higher than in the bulk (Figure 1). Even after averaging over three solvation shells, the local densities obtained by computer simulation can exceed the bulk value by as much as 50\% (Knutson et al., 1991). Furthermore, the effect occurs over a wide density range that includes (but is not limited to) the solvent's critical point.

At a reduced temperature of 1.02 (or, equivalently, at a temperature of $37^{\circ} \mathrm{C}$, six degrees above carbon dioxide's critical point), the simulations revealed a wide range of densities across which significant local density enhancements with respect to bulk conditions occur around the solute (Figure 2). When quantified in terms of a ratio of local to bulk density, this effect is more pronounced when the bulk density is $1 / 3$ of the critical density. Under these consitions, the local density exceeds the bulk value by $100 \%$ in the first solvation shell, and by $45 \%$ when it is averaged over as much as, three solvation shells (Knutson et al., 1991). 
We obtained excellent, quantitative agreement between spectroscopic estimates and simulation determinations of local density enhancements when we computed the effect over one solvation shell (Figure 3 ). This means that the length scale probed by fluorescence spectra is one solvation shell (ca. $7.5 \mathrm{~A}$ ).

We believe that these results are very significant. They provide direct (and quantitative) evidence of pronounced local density enhancements in supercritical mixtures. They show that fluorescence spectra are influenced by solute-solvent interactions occurring over one solvation shell. They show that the phenomenon of local density enahncements occurs over a wide density range including (but not limited to) the solvent's critical point, but tends to disappear if the temperature is increased beyond $10 \%$ above the critical point. For carbon dioxide, this means that density augmentations are important across the entire range of temperatures between 30 and $60^{\circ} \mathrm{C}$ (where most practical applications occur).

The direct comparison between simulation and experiment confirms that in highly asymmetric supercritical systems, bulk and local conditions can differ dramatically. This effect tends to disappear at both high and low densities. In the former case, as the solvent becomes liquid-like, it also becomes incompressible, and density enhancements become progressively weaker. At the other extreme, interactions become progressively irrelevant as the solvent approaches ideal gas behavior.

In addition to the work on supercritical mixtures, we have developed new algorithms for the efficient simulation of large systems (Chialvo and Debenedetti, 1990, 1991a), and we have shown that the hitherto neglected McQuarrie equation for the computation of shear viscosity in equilibrium molecular dynamics has significant numerical advantages with respect to alternative formulations (Chialvo and Debenedetti, $1991 \mathrm{~b})$.

\section{FUTURE WORK}

The most severe idealization that we have used in the simulations so far is that of infinite dilution. There is a growing body of evidence that suggests that solute-solute interactions can be very important (even at high dilution) at supercritical conditions (Kurnik and Reid, 1982; Randolph et al., 1988 a,b; Brennecke and Eckert, 1988). Therefore, our next objective will be to simulate supercritical mixtures taking into account solute-solute interactions. In order to do this while maintaining the requirement of diluteness (small solute mole fraction), we need to simulate large systems (typically 10,000 molecules, of which ca. $10-20$ are solute; normally, simulations involve less than 1,000 particles).

Comparison will be made with excimer fluorescence experiments currently under way at Georgia Tech. In these experiments, excimer (excited state dimer) formation is detected spectroscopically, and is observed, at supercritical conditions, even at solute mole fractions as low as $10^{-6}$. Our simulations will track association statistics (dimer, trimer, tetramer, etc.); specifically, we will calculate the concentration and lifetimes of solute-solute aggregates. Tracking these quantities as a function of density and temperature will allow us to investigate in great detail the importance of solute-solute interactions in supercritical systems. We are particularly 
interested in comparing the loss of excimer signal in spectroscopic experiments with aggregate formation (or lack thereof) in simulations.

\section{Literature Cited}

Brennecke, J.F.; Eckert, C.A. Proc. int. Symp. Supercrit. Fluids (I) Nice, France, $1988,263$.

Brennecke, J.F.; Eckert, C.A. AlChEJ. 1989a, 35, 1409.

Brennecke, J.F.; Eckert, C.A. In Supercritical Fluid Science and Technology; ACS Symposium Series 406; Johnston, K.P., Penninger, J.M.L. Eds., American Chemical Society: Washingtorı, D.C., 1989b; Ch. 5.

Bronnecke, J.F.; Tomasko, D.L.; Peshkin, J.; Eckert, C.A. Ind. Eng. Chem. Res. 1990a, $29,1682$.

Brennecke, J.F.; Tomasko, D.L.; Eckert, C.A. J. Phys. Chem. 1990b, 94, 7692.

Chialvo, A.A.; Debenedetti, P.G. Computer Phys. Commun. 1990, 60, 215.

Chialvo, A.A.; Debenedetti, P.G. Computer Phys. Commun. 1991a, 64, 15.

Chialvo, A.A.; Debenedetti, P.G. Phys. Rev. A 1991b, 43, 4289.

Cochran, H.D., Lee, L.L. In Supercritical Fluid Science and Technology; ACS Symposium Series 406; Johnston, K.P., Penninger, J.M.L. Eds., American Chemical Society: Washington, D.C., 1989b; Ch. 3.

Kim, S.; Johnston, K.P. AIChEJ. 1987a, 33, 1603.

Kim, S.; Johnston, K.P. Ind. Eng. Chem. Res. 1987b, 26, 1206.

Knutson, B.L.; Tomasko, D.L.; Eckert, C.A.; Chialvo, A.A.; Debenedetti, P.G. In Recent Advances in Supercritical Fluid Technology. Applications and Fundamental Studies; ACS Symposium Series; Bright, F., McNally, M.E.P., Eds., submitted, 1991.

Kurnik, R.T.; Reid, R.C. Fluid Phase Equilib. 1982, 8, 93.

Petsche, I.B.; Debenedetti, P.G. J. Chem. Phys. 1989, 91, '7075.

Petsche, I.B.; Debenedetti, P.G. J. Phys. Chem. 1991, 95, 386.

Randolph, T.W.; Clark, D.S.; Blanch, H.W.; Prausnitz, J.M. Science, 1988a, 238, 387.

Randolph, T.W.; Blanch, H.W.; Prausnitz, J.M. AlChEJ. 1988b, 34, 1354.

Wu, R.S.; Lee, L.L.; Cochran, H.D. Ind. Eng. Chem. Res. 1990. 29, 977. 
111. PUBLICATIONS RESULTING FROM THIS GRANT DURING THE PERIOD 7/31/90Z/31/91

Chialvo, A.A.; Debenedetti, P.G. "On the Use of the Verlet Neighbor List in Molecular Dynamics". Computer Phys. Commun. 1990, 60, 215.

Chialvo, A.A.; Debenedetti, P.G. "On the Performance of an Automated Verlet Neightor List Algorithm for Large Systems on a Vector Processor". Computer Phys. Commun. $1991,64,15$.

Chialvo, A.A.; Debenedetti, P.G. "Use of the McQuarrie Equation for the Computation of Shear Viscosity via Equilibrium Molecular Dynamics". Phys. Rev. A 1991, 43, 4289.

Chialvo, A.A.; Debenedetti, P.G. "A Study of Solute-Solvent Interactions At Infinite Dilution via the Coupling Parameter Approach". Molecular Simulation 1991 (in press).

IV. MANUSCRIPTS RELATED TO THIS GRANT SUBMITTED BETWEEN 7/31/90 AND 7/31/91

Knutson, B.L.; Tomasko, D.L.; Eckert, C.A.; Chialvo, A.A.; Debenedetti, P.G. "Local Density Augmentation in Supercritical Solutions: A Comparison Between Fluorescence Spectroscopy and Molecular Dynamics Results". In Recent Advances in Supercritical Fluid Technology. Applications and Fundamental Studies; ACS Symposium Series; Bright, F., McNally, M.E.P., Eds., submitted, 1991.

Chialvo, A.A.; Debenedetti, P.G. " Solute-Solute Correlations in Infinitely Dilute NearCritical Mixtures". J. Phys. Chem. 1991, submitted. 


\section{FIGURE CAPTIONS}

Figure 1: Relationship between local and bulk densities at two supercritical temperatures $\left[T / T_{C}=1.02\right.$ (filled symbols); 1.145 (empty symbols)] for infinitely dilute pyrene in carbon dioxide. To convert to molar densities in moles/liter, the dimensioniess densities must be multiplied by 30.4 . $R^{*}$ denotes the dimensionless radial distance away from the pyrene molecule over which local densities were computed. To convert to distances in $A$, multiply by 3.794 . $T^{*}$ denotes the quantity $k T / \varepsilon$, where $\varepsilon$ is the solvent's characteristic energy parameter. Molecular dynamics simulation.

Figure 2: Relationship between local density enhancement (defined as local/bulk density) and bulk density. $T / T_{C}=1.02$ (open symbols); 1.145 (filled symbols). Other conditions and units as per Figure 1.

Figure 3: Comparison between spectroscopic (circles) and molecular dynamics (squares) determinations of local density enhancements in the system pyrene/carbon dioxide at $37^{\circ} \mathrm{C}$. 


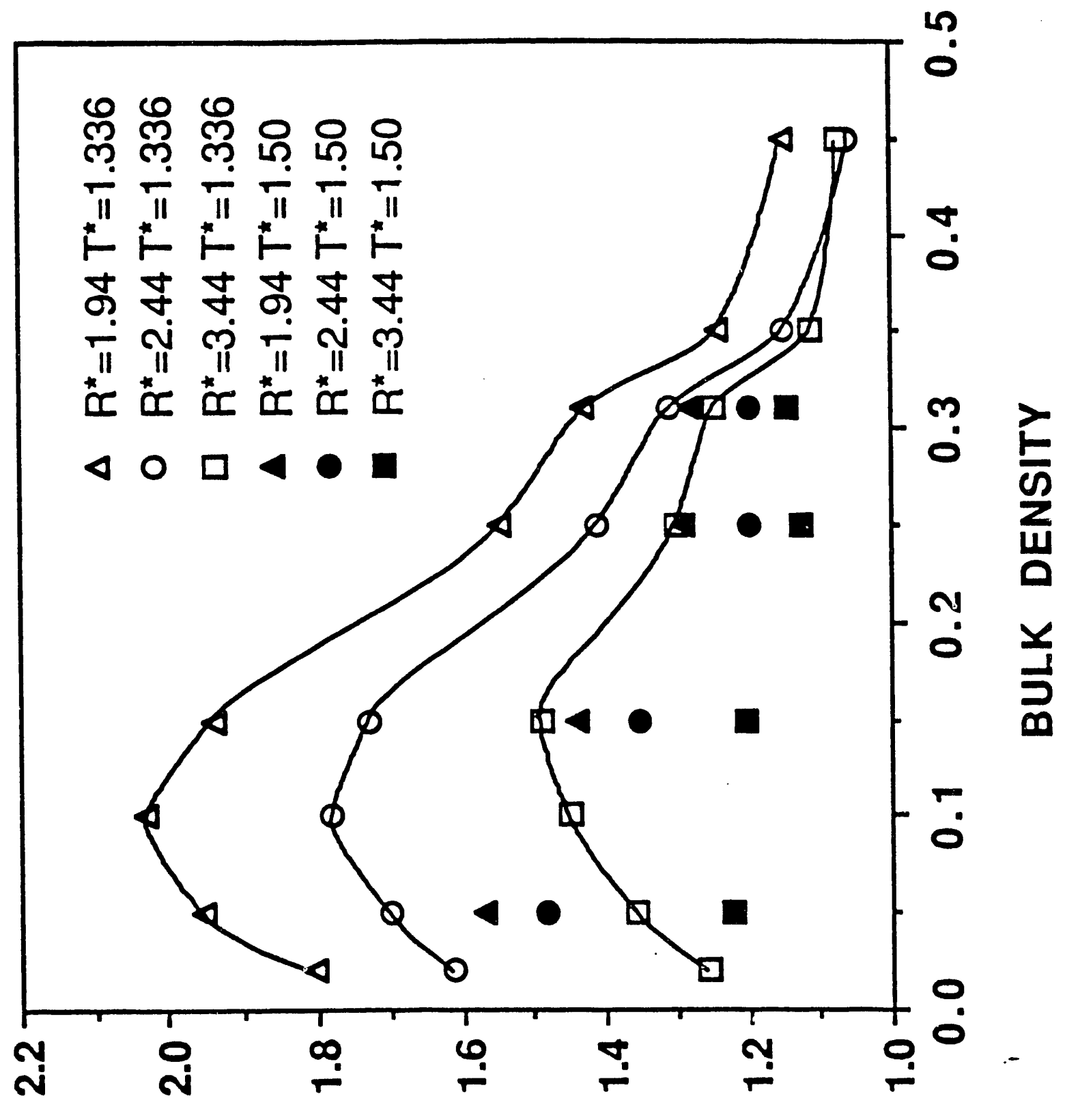

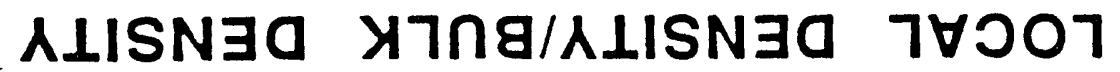




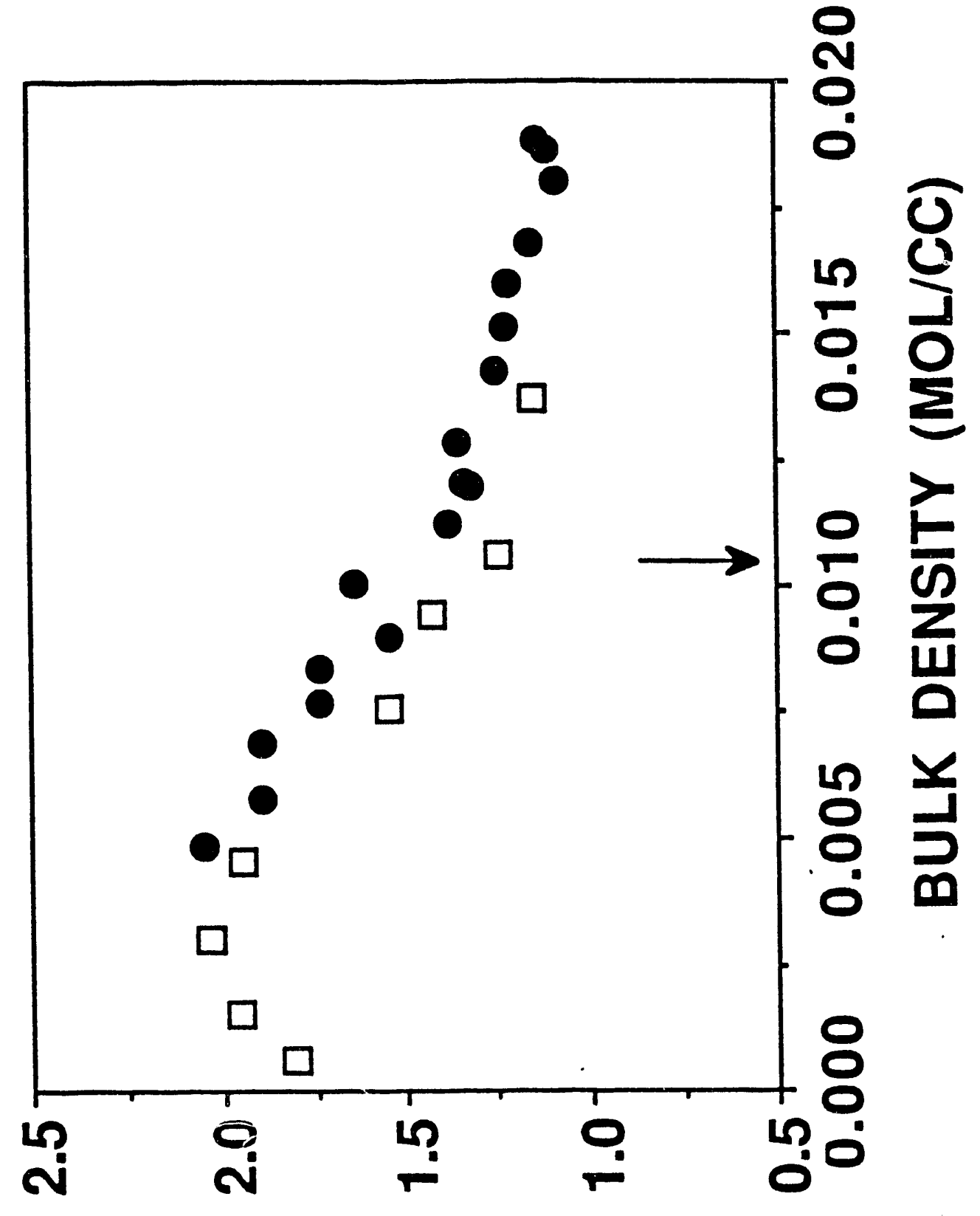

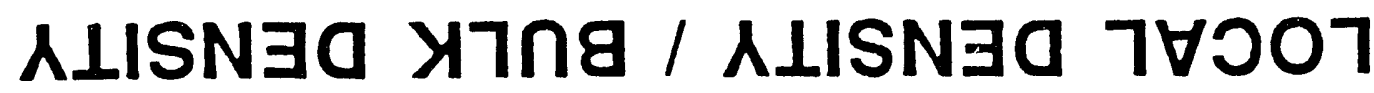



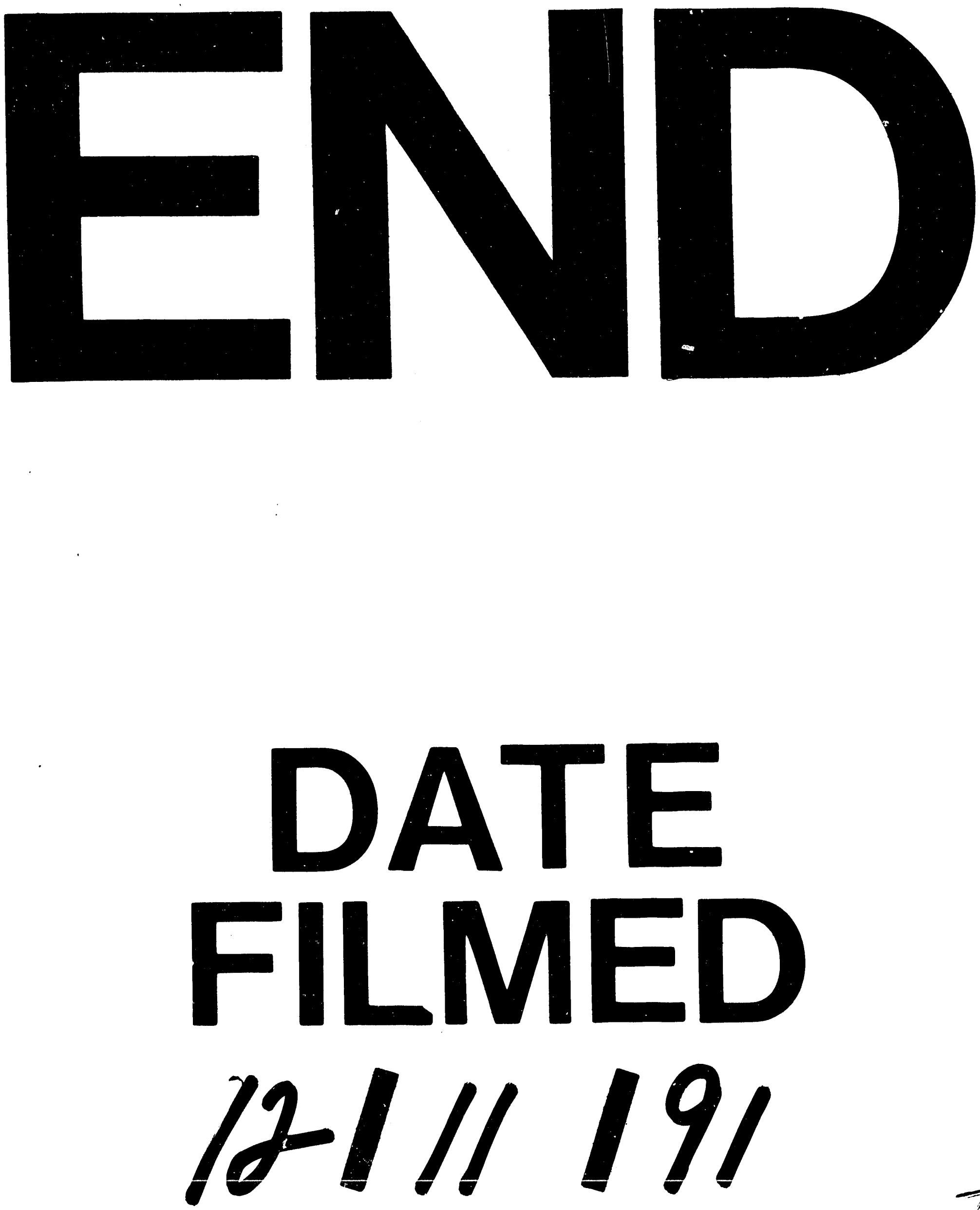

" 
. 